\title{
Respons Pertumbuhan Dua Varietas Padi Lokal dengan Beberapa Komposisi Kompos
}

\section{Growth Response of Two Local Rice Varieties with Compositional Giving}

\section{Ryan Richo M, Chariani Hanum*, Meiriani}

Program Studi Agroteknologi, Fakultas Pertanian, USU, Medan 20155

*Corresponding author : hanum_chairani@yahoo.com

\begin{abstract}
Development of local rice is currently still lacking because the productivity is relatively low compared with wetland rice. In fact, local varieties have a high adaptability of conformity to a local area, local varieties also need to be preserved as a germplasm, as well as sources of genetic biodiversity. One of the alternatives to increase the growth and productivity of local rice was by developing compost technology. The purpose of this study was to study the growth and production of two local rice varieties on growing media compost treatment. The research conduct on the Village Paya Bakung Kec. Hamparan Perak, Kab. Deli Serdang with altitude of place \pm 25 meters above sea level in March to September 2016. This research was conducted by using factorial randomized block design (RRBL) with 2 factors. The first factor was compost treatment with 5 levels were: $0 \mathrm{~kg} /$ plot compost; blotong 3,6 kg/plot; EFBOP 3,6 kg/plot; blotong 3,6 kg/plot + EFBOP 3,6kg/plot; blotong 7,2 kg/plot + EFBOP 3,6 kg/plot; blotong 3,6 kg/plot + EFBOP 7,2 $\mathrm{kg} / \mathrm{plot}$. The second fator was variety of upland rice, were: Sikembiri and Sigendek-gendek. The results showed that each variety had a difference in plant height while compost treatment will increase plant height, and number of tillers per clump. Combination of plant media treatment (blotong 7,2 kg/plot + EFBOP $3.6 \mathrm{~kg} /$ plot) on Sikembiri and Sigendek-gendek has the highest of plant height.
\end{abstract}

Keywords: Upland rice, growth, compost blotong, EFBOP

\begin{abstract}
ABSTRAK
Pengembangan padi lokal saat ini masih kurang mendapat perhatian karena produktivitasnya masih tergolong rendah dibandingkan dengan padi sawah. Padahal, varietas lokal memiliki adaptasi kesesuaian yang tinggi terhadap daerah tertentu, varietas lokal juga perlu dipertahankan dan dilestarikan sebagai kekayaan plasma nutfah, sekaligus sumber keragaman genetik. Salah satu alternatif untuk meningkatkan pertumbuhan dan produktivitas padi lokal adalah dengan pengembangan teknologi penggunaan kompos. Tujuan dari penelitian ini adalah untuk mempelajari pertumbuhan dan produksi dua varietas padi lokal dengan pemberian beberapa komposisi kompos. Untuk itu dilakukan penelitian di Desa Paya Bakung Kec. Hamparan Perak, Kab. Deli Serdang dengan ketinggian tempat \pm 25 meter di atas permukaan laut pada bulan Maret hingga September 2016. Penelitian ini dilakukan dengan menggunakan rancangan acak kelompok faktorial (RAK) dengan 2 faktor. Faktor pertama adalah media tanam kompos dengan 5 taraf yaitu: tanpa pemberian kompos (0 kg/plot) ; kompos blotong 3,6 kg/plot; kompos TKKS 3,6 kg/plot; kompos blotong 3,6 kg/plot + kompos TKKS 3,6kg/plot; kompos blotong 7,2 kg/plot + kompos TKKS 3,6 kg/plot; kompos 3,6 kg/plot + kompos TKKS 7,2 kg/plot. Faktor II adalah varietas padi gogo, terdiri dari varietas Sikembiri dan Sigendek-gendek. Hasil penelitian menunjukkan bahwa masing-masing varietas memiliki perbedaan tinggi tanaman sementara perlakuan kompos nyata meningkatkan tinggi tanaman, dan jumlah anakan per rumpun. Kombinasi perlakuan media tanaman (blotong 7,2 kg/plot + TKKS 3,6 kg/plot) pada varietas Sikembiri dan Sigendek gendek menghasilkan rataaan tertinggi dari tinggi tanaman.
\end{abstract}

Kata kunci: Padi gogo, pertumbuhan, kompos blotong, kompos TKKS 


\section{PENDAHULUAN}

Keberadaan varietas lokal saat ini kurang diperhitungkan karena memiliki penampilan populasi yang beragam seperti bentuk dan warna gabah yang kurang baik, umur panen yang relatif lama (110-150 hari), dan tinggi tanaman (120-150 $\mathrm{cm})$ serta tingginya tingkat kerebahan.. Padahal, varietas lokal memiliki adaptasi kesesuaian yang tinggi terhadap daerah tertentu. Varietas lokal perlu dipertahankan dan dilestarikan sebagai kekayaan plasma nutfah daerah, sekaligus sumber keragaman genetik. (Ginting, 2010).

Salah satu alternatif untuk meningkatkan pertumbuhan dan produktivitas tanaman padi adalah memperbaiki kondisi tanah dan lingkungan. Yaitu dengan menggunakan pupuk organik (kompos) dan atau pupuk hayati. Pupuk organik yang dapat digunakan antara lain blotong dan tandan kosong kelapa sawit (TKKS) (Suwarto dan Agung, 2011).

Pusat Penelitian Kelapa sawit (PPKS) melakukan teknologi pengomposan dengan memanfaatkan hasil limbah pabrik menjadi kompos. Bahan yang diperlukan untuk produksi kompos tersebut adalah limbah Tandan Kosong Kelapa Sawit (TKKS) dan limbah cair pabrik kelapa sawit. Contoh gambaran, apabila sebuah pabrik kelapa sawit dengan kapasitas 30 ton/jam akan menghasilkan LCPKS $360 \mathrm{~m}^{3} /$ hari dan TKKS $138 \mathrm{~m}^{3} /$ hari sehingga hasil perpaduan kedua limbah tersebut akan diolah menghasilkan kompos TKKS sebesar 70 ton/hari.

(PPKS, 2008).

Keunggulan kompos TKKS meliputi: kandungan kalium yang tinggi, tanpa penambahan starter dan bahan kimia, memperkaya unsur hara yang ada di dalam tanah, dan mampu memperbaiki sifat fisik, kimia dan biologi. Selain itu kompos TKKS memiliki beberapa sifat yang menguntungkan antara lain: (1) memperbaiki struktur tanah berlempung menjadi ringan; (2) membantu kelarutan unsurunsur hara yang diperlukan bagi pertumbuhan tanaman; (3) bersifat homogen dan mengurangi risiko sebagai pembawa hama tanaman; (4) merupakan pupuk yang tidak mudah tercuci oleh air yang meresap dalam tanah dan (5) dapat diaplikasikan pada sembarang musim (Darnoko dan Sutarta, 2006).
Blotong atau disebut "filtermud" adalah kotoran nira tebu dari proses pembuatan gula yang disebut sebagai by product. Persentase blotong yang dihasilkan dari tiap hektar pertanaman tebu yaitu sekitar $4-5 \%$. Persentase kotoran nira ini cukup tinggi yaitu $9-18 \%$ dari tebu (Purwaningsih, 2011).

Berdasarkan uraian diatas, penulis tertarik untuk melakukan penelitian mengenai pengaruh pemberian kompos TKKS dan kompos blotong terhadap pertumbuhan dan produksi tanaman padi lokal.

\section{BAHAN DAN METODE}

Penelitian dilaksanakan di lahan milik petani di Desa Paya Bakung Kec. Hamparan Perak, Kab. Deli Serdang (koordinat $03^{\circ} 03^{\prime} 40^{\prime \prime}$ $03^{\circ} 40^{\prime} 02^{\prime \prime} \mathrm{U}$ dan $98^{\circ} 27^{\prime} 03^{\prime \prime}-98^{\circ} 39^{\prime} 32^{\prime \prime} \mathrm{T}$ ) dengan ketinggian tempat \pm 25 meter di atas permukaan laut pada bulan Maret 2016 hingga September 2016. Bahan yang digunakan dalam penelitian ini adalah benih padi gogo varietas Sikembiri dan Sigendak-gendak, TSP, $\mathrm{KCl}$, kompos TKKS, kompos blotong, insektisida Decis 50 EC untuk mengendalikan hama, Antracol $70 \mathrm{WP}$, dan bahan-bahan lainnya yang mendukung penelitian ini. Penelitian ini dilakukan dengan menggunakan rancangan acak kelompok faktorial (RAK) dengan 2 faktor yaitu faktor I adalah Kompos (K) dengan 5 taraf yaitu $\mathrm{K} 0$ : tanpa pemberian kompos $\left(0\right.$ ton/Ha) $; \mathrm{K}_{1}$ : kompos blotong 6 ton/ $\mathrm{Ha}(3,6 \mathrm{~kg} / \mathrm{plot}) ; \mathrm{K}_{2}$ : kompos TKKS 6 ton/Ha $(3,6 \mathrm{~kg} / \mathrm{plot}) ; \mathrm{K}_{3}$ : kompos blotong 6 ton/Ha $(3,6 \mathrm{~kg} / \mathrm{plot})+$ kompos TKKS 6 ton $/ \mathrm{Ha}(3,6 \mathrm{~kg} / \mathrm{plot}) ; \mathrm{K}_{4}$ : kompos blotong 12 ton/Ha (7,2 kg/plot) + kompos TKKS 6 ton/Ha(3,6 kg/plot); $\mathrm{K}_{5}$ : kompos blotong 6 ton/Ha (3.6 kg/plot) + kompos TKKS 12 ton/Ha $(7,2 \mathrm{~kg} / \mathrm{plot})$. Faktor II adalah varietas, terdiri dari varietas Sikembiri $\left(\mathrm{V}_{1}\right)$ dan Sigendek-gendek $\left(\mathrm{V}_{2}\right)$.

\section{HASIL DAN PEMBAHASAN}

\section{Tinggi Tanaman}

Komposisi kompos berpengaruh nyata terhadap tinggi tanaman dan varietas padi pada umur 2, 10 dan 12 MST, sedangkan serta interaksi keduanya berpengaruh nyata pada umur 4 dan 6 MST. 
Tabel 1. Tinggi dua varietas padi dengan pemberian beberapa komposisi kompos pada umur 2-12 MST

\begin{tabular}{|c|c|c|c|c|}
\hline \multirow{3}{*}{ Umur } & \multirow{3}{*}{ Kompos } & \multicolumn{2}{|c|}{ Varietas } & \multirow{3}{*}{ Rataan } \\
\hline & & $\frac{\mathrm{V}_{1}}{\mathrm{C} \cdot 1}$ & $\mathrm{~V}_{2}$ & \\
\hline & & Sikembiri & Sigendek-sigendek & \\
\hline \multirow{7}{*}{$2 \mathrm{MST}$} & & & ....cm.. & \\
\hline & $\mathrm{K}_{0}(0 \mathrm{~kg} / \mathrm{plot})$ & 18,49 & 19,28 & $18,89 \mathrm{bc}$ \\
\hline & $\mathrm{K}_{1}$ (kompos blotong 3,6 kg/plot) & 16,25 & 20,48 & $18,36 \mathrm{bc}$ \\
\hline & $\mathrm{K}_{2}$ (kompos TKKS 3,6 kg/plot) & 17,33 & 20,12 & $18,73 \mathrm{bc}$ \\
\hline & $\mathrm{K}_{3}$ (kompos blotong 3,6 kg/plot + kompos TKKS 3,6 kg/plot) & 19,59 & 19,55 & $19,57 \mathrm{bc}$ \\
\hline & $\mathrm{K}_{4}$ (kompos blotong 7,2 kg/plot + kompos TKKS 3,6 kg/plot) & 21,81 & 22,67 & 22,24 a \\
\hline & $\mathrm{K}_{5}$ (kompos blotong 3,6 kg/plot + kompos TKKS 7,2 kg/plot) & 20,91 & 20,99 & $20,95 \mathrm{ab}$ \\
\hline & Rataan & $21,36 \mathrm{~b}$ & $21,83 \mathrm{a}$ & 43,19 \\
\hline \multirow{7}{*}{$4 \mathrm{MST}$} & $\mathrm{K}_{0}(0 \mathrm{~kg} / \mathrm{plot})$ & $29,93 \mathrm{~d}$ & $29,47 \mathrm{~d}$ & 29,70 \\
\hline & $\mathrm{K}_{1}$ (kompos blotong 3,6 kg/plot) & $30,45 \mathrm{~cd}$ & $33,49 a b$ & 31,97 \\
\hline & $\mathrm{K}_{2}$ (kompos TKKS 3,6 kg/plot) & $30,25 \mathrm{~d}$ & $32,99 \mathrm{abc}$ & 31,62 \\
\hline & $\mathrm{K}_{3}$ (kompos blotong 3,6 kg/plot + kompos TKKS 3,6 kg/plot) & $33,73 \mathrm{ab}$ & $30,82 \mathrm{~cd}$ & 32,27 \\
\hline & $\mathrm{K}_{4}$ (kompos blotong 7,2 kg/plot + kompos TKKS 3,6 kg/plot) & 34,02 a & 34,92 a & 34,47 \\
\hline & $\mathrm{K}_{5}$ (kompos blotong 3,6 kg/plot + kompos TKKS 7,2 kg/plot) & $31,60 \mathrm{bcd}$ & 31,43 bcd & 31,52 \\
\hline & Rataan & 31,66 & 31,66 & 32,18 \\
\hline \multirow{7}{*}{$6 \mathrm{MST}$} & $\mathrm{K}_{0}(0 \mathrm{~kg} / \mathrm{plot})$ & $45,75 \mathrm{e}$ & $49,80 \mathrm{e}$ & 47,77 \\
\hline & $\mathrm{K}_{1}$ (kompos blotong 3,6 kg/plot) & 55,17 bcd & $56,71 \mathrm{abc}$ & 55,95 \\
\hline & $\mathrm{K}_{2}$ (kompos TKKS 3,6 kg/plot) & 55,22 bcd & $57,27 \mathrm{abc}$ & 56,24 \\
\hline & $\mathrm{K}_{3}$ (kompos blotong 3,6 kg/plot + kompos TKKS 3,6 kg/plot) & $57,60 \mathrm{ab}$ & $54,57 \mathrm{~cd}$ & 56,09 \\
\hline & $\mathrm{K}_{4}$ (kompos blotong 7,2 kg/plot + kompos TKKS 3,6 kg/plot) & 58,30 a & $57,93 \mathrm{ab}$ & 58,11 \\
\hline & $\mathrm{K}_{5}$ (kompos blotong 3,6 kg/plot + kompos TKKS 7,2 kg/plot) & $56,15 \mathrm{abc}$ & $52,83 \mathrm{de}$ & 54,49 \\
\hline & Rataan & 54,70 & 54,85 & 109,55 \\
\hline \multirow{7}{*}{$8 \mathrm{MST}$} & $\mathrm{K}_{0}(0 \mathrm{~kg} / \mathrm{plot})$ & 98,55 & 97,09 & $97,82 \mathrm{~b}$ \\
\hline & $\mathrm{K}_{1}$ (kompos blotong 3,6 kg/plot) & 103,03 & 96,19 & $99,61 \mathrm{~b}$ \\
\hline & $\mathrm{K}_{2}$ (kompos TKKS 3,6 kg/plot) & 103,05 & 99,78 & $101,42 \mathrm{~b}$ \\
\hline & $\mathrm{K}_{3}$ (kompos blotong 3,6 kg/plot + kompos TKKS 3,6 kg/plot) & 107,00 & 103,84 & $105,42 \mathrm{~b}$ \\
\hline & $\mathrm{K}_{4}$ (kompos blotong 7,2 kg/plot + kompos TKKS 3,6 kg/plot) & 115,25 & 115,63 & $115,44 \mathrm{a}$ \\
\hline & $\mathrm{K}_{5}$ (kompos blotong 3,6 kg/plot + kompos TKKS 7,2 kg/plot) & 106,13 & 105,32 & $105,72 \mathrm{~b}$ \\
\hline & Rataan & 105,50 & 102,97 & 208,48 \\
\hline \multirow{7}{*}{$10 \mathrm{MST}$} & $\mathrm{K}_{0}(0 \mathrm{~kg} / \mathrm{plot})$ & 120,57 & 104,51 & $112,54 \mathrm{~b}$ \\
\hline & $\mathrm{K}_{1}$ (kompos blotong 3,6 kg/plot) & 116,79 & 109,43 & $113,11 \mathrm{~b}$ \\
\hline & $\mathrm{K}_{2}$ (kompos TKKS 3,6 kg/plot) & 121,02 & 109,60 & $115,31 \mathrm{~b}$ \\
\hline & $\mathrm{K}_{3}$ (kompos blotong 3,6 kg/plot + kompos TKKS 3,6 kg/plot) & 121,79 & 112,51 & $117,15 \mathrm{~b}$ \\
\hline & $\mathrm{K}_{4}$ (kompos blotong 7,2 kg/plot + kompos TKKS 3,6 kg/plot) & 132,25 & 130,28 & $131,27 \mathrm{a}$ \\
\hline & $\mathrm{K}_{5}$ (kompos blotong 3,6 kg/plot + kompos TKKS 7,2 kg/plot) & 119,58 & 113,12 & $116,35 \mathrm{~b}$ \\
\hline & Rataan & $122,00 \mathrm{a}$ & $113,24 \mathrm{~b}$ & 235,24 \\
\hline \multirow{7}{*}{$12 \mathrm{MST}$} & $\mathrm{K}_{0}(0 \mathrm{~kg} / \mathrm{plot})$ & 123,18 & 105,67 & $114,42 \mathrm{~b}$ \\
\hline & $\mathrm{K}_{1}$ (kompos blotong 3,6 kg/plot) & 119,47 & 111,86 & $115,67 \mathrm{~b}$ \\
\hline & $\mathrm{K}_{2}$ (kompos TKKS 3,6 kg/plot) & 123,18 & 111,66 & $117,42 \mathrm{~b}$ \\
\hline & $\mathrm{K}_{3}$ (kompos blotong 3,6 kg/plot + kompos TKKS 3,6 kg/plot) & 125,05 & 111,51 & $118,28 \mathrm{~b}$ \\
\hline & $\mathrm{K}_{4}$ (kompos blotong 7,2 kg/plot + kompos TKKS 3,6 kg/plot) & 134,61 & 132,81 & $133,71 \mathrm{a}$ \\
\hline & $\mathrm{K}_{5}$ (kompos blotong 3,6 kg/plot + kompos TKKS 7,2 kg/plot) & 121,29 & 117,99 & $119,64 \mathrm{~b}$ \\
\hline & Rataan & $124,46 \mathrm{a}$ & $115,25 \mathrm{~b}$ & 239,71 \\
\hline
\end{tabular}

Tabel 1 menunjukkan bahwa interaksi komposisi kompos $\mathrm{K}_{4}$ (kompos blotong 7,2 $\mathrm{kg} / \mathrm{plot}+$ kompos TKKS 3,6 kg/plot) dan varietas $\mathrm{V}_{2}$ (Sigendek-gendek) berpengaruh nyata pada tinggi tanaman 4 dan 6 MST. Pada Tabel 1 dapat dilihat bahwa pada $4 \mathrm{MST}$ interaksi $\mathrm{K}_{4} \mathrm{~V}_{2}$ berbeda nyata dengan perlakuan lainnya dengan nilai 34,92 dan diikuti oleh $\mathrm{K}_{4} \mathrm{~V}_{1}$ 34,02. Pada 6 MST 
interaksi $\mathrm{K}_{4} \mathrm{~V}_{2}$ dan $\mathrm{K}_{4} \mathrm{~V}_{1}$ berbeda nyata dengan perlakuan lainnya dengan nilai berturut turut 58,30 dan 57,93. Dari sini dapat kita lihat bahwa pada pertumbuhan vegetatif padi minggu ke 4 dan 6 MST kedua varietas padi yang digunakan memiliki pertumbuhan yang sama baik namun sangat dipengaruhi dengan komposisi bahan organik yang diberikan, dalam hal ini komposisi bahan organik pada perlakuan $\mathrm{K}_{4}$ (kompos blotong 7,2 kg/plot + kompos TKKS 3,6 kg/plot) memberikan hasil pertumbuhan tinggi tanaman yang baik dibandingkan dengan komposisi yang lainnya. Pemberian dosis bahan organik yang optimal dapat memberikan pengaruh yang tertinggi terhadap pertumbuhan vegetatif tanaman. Hal ini dikarenakan perpaduan dosis kompos ini menunjukkan kandungan kimia tanah yang sesuai untuk pertumbuhan tanaman serta perbaikan sifat fisik tanah terutama di lapisan penebaran kompos. Sastraatmadja, Widawati dan Rachmat (2001) menyatakan bahwa pupuk organik seperti kompos adalah pupuk alami yang dapat menambah unsur hara di dalam tanah. Kompos mempunyai kemampuan menyerap air dan mempunyai kandungan unsur-unsur mikro dan makro yang dibutuhkan oleh tanaman.

Tabel 2. Jumlah anakan per rumpun dua varietas padi dengan pemberian beberapa kompos pada umur 4-12 MST

\begin{tabular}{|c|c|c|c|}
\hline \multirow{3}{*}{ Kompos } & \multicolumn{2}{|c|}{ Varietas } & \multirow{3}{*}{ Rataan } \\
\hline & \multirow{2}{*}{$\frac{\mathrm{V}_{1}}{\text { Sikembiri }}$} & \multirow{2}{*}{$\begin{array}{c}\mathrm{V}_{2} \\
\text { Sigendek-gendek }\end{array}$} & \\
\hline & & & \\
\hline & & ........... anakan... & \\
\hline $\mathrm{K}_{0}(0 \mathrm{~kg} / \mathrm{plot})$ & 3,05 & 2,44 & $2,75 \mathrm{~b}$ \\
\hline $\mathrm{K}_{1}$ (kompos blotong 3,6 kg/plot) & 2,61 & 2,72 & $2,66 \mathrm{~b}$ \\
\hline $\mathrm{K}_{2}($ kompos TKKS $3,6 \mathrm{~kg} / \mathrm{plot})$ & 3,05 & 3,05 & $3,05 \mathrm{~b}$ \\
\hline $\mathrm{K}_{3}$ (kompos blotong 3,6 kg/plot + kompos TKKS 3,6 kg/plot) & 3,33 & 2,94 & $3,14 \mathrm{~b}$ \\
\hline $\mathrm{K}_{4}$ (kompos blotong $7,2 \mathrm{~kg} / \mathrm{plot}+$ kompos TKKS $\left.3,6 \mathrm{~kg} / \mathrm{plot}\right)$ & 3,83 & 3,89 & $3,86 \mathrm{a}$ \\
\hline $\mathrm{K}_{5}$ (kompos blotong 3,6 kg/plot + kompos TKKS 7,2 kg/plot) & 2,88 & 2,77 & $2,83 \mathrm{~b}$ \\
\hline Rataan & 3,13 & 2,97 & 6,10 \\
\hline $\mathrm{K}_{0}(0 \mathrm{~kg} / \mathrm{plot})$ & 3,94 & 3,49 & $3,72 b$ \\
\hline $\mathrm{K}_{1}$ (kompos blotong 3,6 kg/plot) & 3,77 & 3,94 & $3,86 \mathrm{~b}$ \\
\hline $\mathrm{K}_{2}$ (kompos TKKS 3,6 kg/plot) & 4,16 & 4,11 & $4,14 b$ \\
\hline $\mathrm{K}_{3}($ kompos blotong $3,6 \mathrm{~kg} / \mathrm{plot}+$ kompos TKKS $3,6 \mathrm{~kg} / \mathrm{plot})$ & 4,44 & 4,00 & $4,22 \mathrm{~b}$ \\
\hline $\mathrm{K}_{4}$ (kompos blotong 7,2 kg/plot + kompos TKKS 3,6 kg/plot) & 4,94 & 4,89 & $4,92 \mathrm{a}$ \\
\hline $\mathrm{K}_{5}$ (kompos blotong 3,6 kg/plot + kompos TKKS 7,2 kg/plot) & 3,83 & 3,94 & $3,89 \mathrm{~b}$ \\
\hline Rataan & 4,18 & 4,06 & 8,24 \\
\hline $\mathrm{K}_{0}(0 \mathrm{~kg} / \mathrm{plot})$ & 7,72 & 6,00 & 6,86 \\
\hline $\mathrm{K}_{1}$ (kompos blotong 3,6 kg/plot) & 7,00 & 6,66 & 6,83 \\
\hline $\mathrm{K}_{2}($ kompos TKKS $3,6 \mathrm{~kg} / \mathrm{plot})$ & 6,61 & 6,89 & 6,75 \\
\hline $\mathrm{K}_{3}($ kompos blotong 3,6 kg/plot + kompos TKKS 3,6 kg/plot) & 6,61 & 8,22 & 7,41 \\
\hline $\mathrm{K}_{4}$ (kompos blotong $7,2 \mathrm{~kg} / \mathrm{plot}+$ kompos TKKS $\left.3,6 \mathrm{~kg} / \mathrm{plot}\right)$ & 9,33 & 8,38 & 8,86 \\
\hline $\mathrm{K}_{5}$ (kompos blotong 3,6 kg/plot + kompos TKKS 7,2 kg/plot) & 7,44 & 8,83 & 8,14 \\
\hline Rataan & 7,45 & 7,50 & 14,95 \\
\hline $\mathrm{K}_{0}(0 \mathrm{~kg} / \mathrm{plot})$ & 8,94 & 6,66 & 7,80 \\
\hline $\mathrm{K}_{1}$ (kompos blotong 3,6 kg/plot) & 8,05 & 7,66 & 7,86 \\
\hline $\mathrm{K}_{2}$ (kompos TKKS $\left.3,6 \mathrm{~kg} / \mathrm{plot}\right)$ & 7,44 & 7,66 & 7,55 \\
\hline $\mathrm{K}_{3}$ (kompos blotong 3,6 kg/plot + kompos TKKS 3,6 kg/plot) & 7,83 & 9,44 & 8,64 \\
\hline $\mathrm{K}_{4}$ (kompos blotong $7,2 \mathrm{~kg} / \mathrm{plot}+$ kompos TKKS $3,6 \mathrm{~kg} / \mathrm{plot}$ ) & 10,4 & 9,78 & 10,08 \\
\hline $\mathrm{K}_{5}$ (kompos blotong 3,6 kg/plot + kompos TKKS 7,2 kg/plot) & 8,61 & 9,50 & 9,05 \\
\hline Rataan & 8,54 & 8,45 & 16,99 \\
\hline $\mathrm{K}_{0}(0 \mathrm{~kg} / \mathrm{plot})$ & 8,88 & 6,55 & 7,72 \\
\hline $\mathrm{K}_{1}$ (kompos blotong 3,6 kg/plot) & 7,89 & 7,27 & 7,58 \\
\hline $\mathrm{K}_{2}($ kompos TKKS $3,6 \mathrm{~kg} / \mathrm{plot})$ & 7,33 & 8,05 & 7,69 \\
\hline $\mathrm{K}_{3}($ kompos blotong 3,6 kg/plot + kompos TKKS 3,6 kg/plot) & 7,89 & 9,78 & 8,83 \\
\hline $\mathrm{K}_{4}$ (kompos blotong $7,2 \mathrm{~kg} / \mathrm{plot}+\mathrm{kompos}$ TKKS $\left.3,6 \mathrm{~kg} / \mathrm{plot}\right)$ & 10,6 & 9,88 & 10,25 \\
\hline $\mathrm{K}_{5}$ (kompos blotong 3,6 kg/plot + kompos TKKS 7,2 kg/plot) & 8,16 & 9,27 & 8,72 \\
\hline Rataan & 8,46 & 8,47 & 16,93 \\
\hline
\end{tabular}




\section{Jumlah Anakan per Rumpun}

Komposisi kompos berpengaruh nyata terhadap jumlah anakan per rumpun pada umur 4 dan 6 MST, sedangkan varietas padi dan interaksi keduanya berpengaruh tidak nyata terhadap jumlah anakan per rumpun yang diamati. Rataan jumlah anakan beberapa varietas padi dengan perlakuan beberapa komposisi kompos dapat dilihat pada Tabel 2 .

Berdasarkan Tabel 2 diketahui bahwa bahan organik berpengaruh nyata terhadap jumlah anakan per rumpun pada umur 4 dan 6 MST sementara pada umur 8-12 MST tidak berbeda nyata. Hal ini sejalan dengan pertambahan tinggi tanaman yang juga nyata di 4 dan 6 MST. Pada umur 4 dan 6 MST rataan tertinggi diperoleh pada padi yang diberi perlakuan $\mathrm{K}_{4}$ (kompos blotong 7,2 kg/plot dan TKKS 3,6 kg/plot).

Hal ini menunjukkan komposisi bahan organik pada perlakuan $\mathrm{K}_{4}$ (kompos blotong 7,2 $\mathrm{kg} / \mathrm{plot}+$ kompos TKKS 3,6 kg/plot) merupakan dosis bahan organik yang optimal dapat memberikan pengaruh yang tertinggi terhadap pertumbuhan vegetatif tanaman. Hal ini disebabkan karena jumlah anakan yang

\section{SIMPULAN}

Pemberian kompos dengan komposisi (kompos blotong 7,2 kg/plot + TKKS 3,6 kg/plot) nyata meningkatkan tinggi tanaman dan jumlah anakan per rumpun pada 4 dan 6 MST. Interaksi beberapa komposisi kompos pada padi varietas Sikembiri berpengaruh nyata terhadap tinggi tanaman. Interaksi beberapa komposisi kompos pada padi varietas Sigendek-gendek berpengaruh nyata terhadap tinggi tanaman.

\section{DAFTAR PUSTAKA}

Darnoko, dan A. S. Sutarta, 2006. Pabrik Kompos di Pabrik Sawit. Penulis dari PPKS (LRPI) Tabloid Sinar Tani, 9 Agustus 2006.

Fatmawati. 2004. Varietas Unggul Padi.http://banten.Litbang.deptan.go.id. [6 Maret 2015].

Ginting. Theresia. H. U. 2010. Pengaruh Pemberian Bokashi Dan Umur dihasilkan oleh tanaman padi gogo dipengaruhi oleh unsur hara makro N, P, dan K. Perbaikan struktur tanah akibat dari aktivitas mikroba dalam kompos dan juga ketersediaan hara $\mathrm{N}$ dan $\mathrm{P}$ yang terkandung di dalam kompos yang cukup mampu memberikan nutrisi bagi pertumbuhan tanaman sehingga dapat memacu tanaman untuk menghasilkan anakan semaksimal mungkin. Hal ini sesuai dengan pernyataan Suhadi et al. (1988) menyatakan bahwa blotong sangat berguna dalam usaha memperbaiki sifat fisik tanah, sehingga daya menahan airnya meningkat. Selain blotong, TKKS juga berperan penting dalam pertumbuhan dan pembentukan anakan padi dengan membantu kelarutan unsur-unsur hara yang terdapat pada blotong. Hal ini sesuai dengan pernyataan Iwan (2012) bahwa kompos TKKS memiliki beberapa sifat yang menguntungkan antara lain membantu kelarutan unsur-unsur hara yang diperlukan bagi pertumbuhan tanaman, bersifat homogen dan mengurangi resiko sebagai pembawa hama tanaman, merupakan pupuk yang tidak mudah tercuci oleh air yang meresap dalam tanah dan dapat diaplikasikan pada sembarang musim.

Pemangkasan Daun Terhadap Pertumbuhan Dan Produksi Padi Lokal Si Kembiri (Oryza Sativa L.). USU Repository. Medan.

Iwan, R. 2012. Tandan Kosong Kelapa Sawit (TKKS) sebagai Alternatif Pupuk Organik. http// blogger gaptek: Tandan Kosong Kelapa Sawit (TKKS) sebagai Alternatif Pupuk Organik. Diakses pada tanggal 09 Februari 2017

Pusat Penelitian Kelapa Sawit. 2008. Kompos Bio Organik Tandan Kosong Kelapa Sawit. Pusat Penelitian Kelapa Sawit. Medan

Purwaningsih, E. 2011. Pengaruh Pemberian Kompos Blotong, Legin,dan Mikoriza Terhadap Serapan Hara N dan P Tanaman Kacang Tanah. Widya Warta 2(35):5568.

Sastraatmadja, D.D, S. Widawati, Rachmat. 2001. Kompos Sebagai Salah Satu Pilihan Dalam Penggunaan Pupuk Organik. Seminar Pelatihan Produk Teknologi 
Unggulan dan Ramah Lingkungan.

UNILA Bandar Lampung.

Suhadi, Sumojo, dan Marsadi. 1988. Beberapa Masalah pada Tanah di Perkebunan

Tebu Lahan Kering di Luar Jawa.

Seminar Budidaya Tebu Lahan Kering.

P3GI, Pasuruan.

Suwarto dan T. Agung, 2011. INPAGO

UNSOED-1 : Varietas Padi Gogo

Unggul Baru, Aromatik dan Produksi

Tinggi. Fakultas Pertanian Unsoed. 